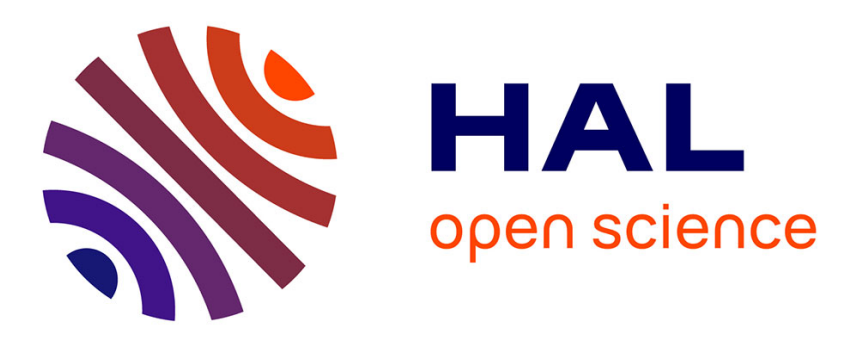

\title{
NDMA Formation by Chloramination of Ranitidine: Kinetics and Mechanism
}

Julien Le Roux, Hervé Gallard, Jean-Philippe Croué, Sébastien Papot, Marie Deborde

\section{- To cite this version:}

Julien Le Roux, Hervé Gallard, Jean-Philippe Croué, Sébastien Papot, Marie Deborde. NDMA Formation by Chloramination of Ranitidine: Kinetics and Mechanism. Environmental Science and Technology, 2012, 46 (20), http://pubs.acs.org/doi/full/10.1021/es3023094. 10.1021/es3023094 . hal01201597

\section{HAL Id: hal-01201597}

https://hal-enpc.archives-ouvertes.fr/hal-01201597

Submitted on 17 Sep 2015

HAL is a multi-disciplinary open access archive for the deposit and dissemination of scientific research documents, whether they are published or not. The documents may come from teaching and research institutions in France or abroad, or from public or private research centers.
L'archive ouverte pluridisciplinaire HAL, est destinée au dépôt et à la diffusion de documents scientifiques de niveau recherche, publiés ou non, émanant des établissements d'enseignement et de recherche français ou étrangers, des laboratoires publics ou privés.

$$
\text { Copyright }
$$




\section{Kinetics and Mechanism}

†Université de Poitiers - CNRS UMR 7285 IC2MP - ENSIP, 1 rue Marcel Doré, 86022 Poitiers Cedex,

France

:Université de Poitiers - CNRS UMR 7285 IC2MP - 4 rue Michel Brunet, 86022 Poitiers Cedex,

8 E-mail addresses: julien.leroux@univ-poitiers.fr (J. Le Roux), herve.gallard@univ-poitiers.fr

(H. Gallard), jp.croue@kaust.edu.sa (J.P. Croué), sebastien.papot@univ-poitiers.fr (S. Papot),

10 marie.deborde@univ-poitiers.fr (M. Deborde)

11 *Phone: +33 (0)5 494544 31; fax: +33 (0)5 494537 68; e-mail: herve.gallard@univ-poitiers.fr.

12 §Present address: King Abdullah University of Science and Technology (KAUST), Thuwal 23955

136900 , Kingdom of Saudi Arabia

\section{ABSTRACT}

15 The kinetics of decomposition of the pharmaceutical ranitidine (a major precursor of NDMA) during chloramination was investigated and some decomposition by-products were identified by using high

17 performance liquid chromatography coupled with mass spectrometry (HPLC-MS). The reaction between

18 monochloramine and ranitidine followed second order kinetics and was acid-catalyzed. Decomposition 19 of ranitidine formed different by-products depending on the applied monochloramine concentration. 
Most identified products were chlorinated and hydroxylated analogues of ranitidine. In excess of

21 monochloramine, nucleophilic substitution between ranitidine and monochloramine led to by-products

22 that are critical intermediates involved in the formation of NDMA, e.g. a carbocation formed from the

23 decomposition of the methylfuran moiety of ranitidine. A complete mechanism is proposed to explain

24 the high formation yield of NDMA from chloramination of ranitidine. These results are of great

25 importance to understand the formation of NDMA by chloramination of tertiary amines.

\section{KEYWORDS}

27 NDMA, Nitrosamine, Chloramination, Disinfection By-products, Ranitidine

\section{$28 \quad$ Introduction}

29 Nitrosamines, especially N-nitrosodimethylamine (NDMA), form during disinfection of drinking 30 waters at near nanogram per liter levels ${ }^{1}$ or wastewaters at concentrations up to several hundred ng/L. ${ }^{2}$

31 They are considered as probable human carcinogens by the US Environmental Protection Agency, ${ }^{3}$ and are listed in the USEPA's Contaminant Candidate List 3. ${ }^{4}$ They can be formed in the presence of nitrites and free chlorine (HOCl-enhanced nitrosation) but are preferentially formed during chloramines

34 disinfection. ${ }^{5}$ Over the last decade, several formation mechanisms have been proposed to explain 35 NDMA formation by chloramination of secondary and tertiary amines. Most of them involve a nucleophilic substitution between dimethylamine (DMA) and monochloramine $\left(\mathrm{NH}_{2} \mathrm{Cl}\right)$ to form an Unsymmetrical Dimethylhydrazine intermediate $(\mathrm{UDMH}){ }^{6,7}$ Dichloramine $\left(\mathrm{NHCl}_{2}\right)$ was proposed to

38 favor the production of NDMA, through the formation of a chlorinated UDMH (UDMH-Cl) 39 intermediate instead of $\mathrm{UDMH}^{8}$ In the presence of bromide ion, it has been suggested that a brominated UDMH (UDMH-Br) would probably be formed. ${ }^{9,10}$ These intermediates were never detected during 41 experiments because they are expected to be rapidly oxidized to NDMA.

42 The contribution of tertiary amines to the production of substantial amounts of NDMA during 43 chloramination has been pointed out. ${ }^{2,11,12}$ In particular, the pharmaceutical ranitidine has been 44 demonstrated to produce high yields of NDMA $(>60 \%) \cdot{ }^{11-13}$ Ranitidine is a histamine H2-receptor 
antagonist used in treatment of peptic ulcer diseases, and was one of the most prescribed drug in the 80 s.

It has been progressively superseded by proton pump inhibitors, but it still remains in the top 15 sold-list of prescribed drugs in different European countries. ${ }^{14}$ Ranitidine has been detected in European and US wastewaters at concentrations ranging from $220 \mathrm{ng} / \mathrm{L}$ to $550 \mathrm{ng} / \mathrm{L} .{ }^{15,16} \mathrm{Such}$ high concentrations in wastewaters could explain the important NDMA formation potentials of wastewaters as compared to model waters containing similar amounts of DMA, ${ }^{2}$ because of the higher conversion rate of ranitidine in NDMA $\left(>60 \%\right.$ as compared to $<3 \%$ for DMA) ${ }^{11,13}$ The presence of a pool of tertiary and quaternary amines acting as NDMA precursors (e.g., pesticides, pharmaceuticals and personal care products) could also participate in the overall NDMA yields observed in wastewaters. ${ }^{13,17}$ Ranitidine has been identified in surface waters of Italy at concentrations ranging from 1 to $10 \mathrm{ng} / \mathrm{L},{ }^{18,19}$ and has been detected in $1.2 \%$ of US streams at $0.01 \mu \mathrm{g} / \mathrm{L} \cdot{ }^{20}$ Several studies have addressed the photochemical degradation of ranitidine in the environment. ${ }^{21,22}$ Several photodecomposition products of ranitidine have been identified, but the by-products formed during the reaction between ranitidine and common oxidants used in water treatment (e.g., chlorine, monochloramine or ozone) have not been investigated.

Many kinetic studies have addressed chlorine reactivity with model compounds but the reactivity of monochloramine with simple model compounds is not well documented. ${ }^{23}$ NDMA formation kinetics of some tertiary amines (i.e., ranitidine, chlorphenamine and doxylamine) have been recently investigated in various matrices. ${ }^{24}$ In this study, real water matrices had a significant impact on NDMA formation kinetics, especially leading to an initial lag period because of competitive reactions between natural organic matter (NOM) and tertiary amines. Studies about the decomposition kinetics of NDMA precursors such as anthropogenic tertiary amines are lacking. Moreover, potential intermediate species involved in the formation of NDMA remain unidentified.

The aim of this study was to investigate the kinetics of decomposition of ranitidine by chloramination and to identify its decomposition by-products by using high performance liquid chromatography coupled with mass spectrometry (HPLC-MS). Reactions were conducted in deionized water to determine the kinetic constants for the reaction between monochloramine and ranitidine in pure solutions; hence 
potential competitive effects of NOM with ranitidine were not studied. The identification of the reaction

by-products should be useful to determine nucleophilic or electrophilic substitution sites in order to better understand the reaction mechanisms leading to the formation of NDMA by chloramination of ranitidine.

\section{Materials and Methods}

Materials. All experiments were conducted using deionized water (Milli-Q, Millipore) buffered with sodium acetate $(\mathrm{pH}=4.0-5.5)$, a mixture of sodium phosphate monobasic and sodium phosphate dibasic $(\mathrm{pH}=7.0-8.5)$, or sodium carbonate $(\mathrm{pH}=10) . \mathrm{pH}$ values were adjusted as needed using sodium hydroxide or sulfuric acid (0.1 N, Fisher Scientific). Ranitidine was supplied through Sigma-Aldrich and was used without further purification. All other reagents were reagent grade or described previously. ${ }^{13}$ All glassware used was washed with deionized water and baked at $500{ }^{\circ} \mathrm{C}$ for at least 5 hours prior to use.

Experimental Methods. Preparation of monochloramine stock solutions was previously described, ${ }^{13}$ and is summarized in the Supporting Information (SI) Text S1. The concentration of monochloramine stock solutions was chosen to get the desired concentration in the working solution. Ranitidine solutions were prepared by dissolving a pre-determined amount of ranitidine in $1 \mathrm{~L}$ of $10 \mathrm{mM}$ acetate, phosphate or carbonate buffer. $100 \mathrm{~mL}$ of monochloramine stock solution was then added to the working solution and reactions were conducted in amber glass bottles at $20^{\circ} \mathrm{C}$, under dark conditions to avoid the photolysis of NDMA. At given contact times, residual oxidants were quenched using a slight excess of sodium thiosulfate $(2 \mathrm{~g} / \mathrm{L})$ and samples were transferred to glass vials for HPLC-MS ${ }^{\mathrm{n}}$ analyses. Most of the experiments were performed using high initial concentrations of ranitidine in order to ensure full detection of the parent compound and its by-products. This level of concentrations was not representative of what can be detected in wastewater treatment plants or environmental samples.

Total Chlorine and Chloramines Analyses. Free chlorine and total chlorine concentrations in the sodium hypochlorite stock solutions were determined by iodometric titration with sodium thiosulfate 0.1 
M (Prolabo, $>99.9 \%$ ). $\mathrm{NH}_{2} \mathrm{Cl}$ and $\mathrm{NHCl}_{2}$ concentrations were determined by spectrophotometric measurement using their respective molar extinction coefficients at $245 \mathrm{~nm}$ and $295 \mathrm{~nm}$ and solving simultaneous equations. ${ }^{25}$ Residual oxidant was analyzed by iodometric titration.

Analyses of Ranitidine and its Chloramination By-products. High performance liquid chromatography coupled with diode array detection and mass spectrometry (HPLC-DAD-MSn ${ }^{\mathrm{n}}$ analyses were performed with a Thermo Surveyor chromatographic system including two detectors: a Thermo Surveyor diode array detector and a Thermo DECA XP Plus ion trap mass spectrometer. Ranitidine and its chloramination by-products were separated using a Phenomenex Luna PFP2 column $(250 \times 4.6 \mathrm{~mm}$, pore size: $100 \AA$, particle size: $5 \mu \mathrm{m})$. The mobile phase consisted in (A) formic acid/methanol (1:1000 $\mathrm{v} / \mathrm{v})$ and $(\mathrm{B})$ formic acid/milliQ water $(1: 1000 \mathrm{v} / \mathrm{v})$ pumped at a flow rate of $0.6 \mathrm{~mL} / \mathrm{min}$. Elution started at $5 \%$ of $\mathrm{A}$ for $5 \mathrm{~min}$, increased to $30 \%$ of $\mathrm{A}$ in $20 \mathrm{~min}$ and holding for $5 \mathrm{~min}$, then increased to $90 \%$ of A in 10 min and holding for $2 \mathrm{~min}$, and then returned to initial conditions. Total run time was $60 \mathrm{~min}$ (including the conditioning of the column to the initial conditions). Injection volume was $100 \mu \mathrm{L}$. All samples were analyzed in full scan mode and $\mathrm{MS}^{2}$ simultaneously. Chemical ionization was performed

111 in atmospheric pressure chemical ionization mode (APCI), in positive and negative mode. The 112 parameters were: capillary temperature of $250{ }^{\circ} \mathrm{C}$, vaporizer temperature $450{ }^{\circ} \mathrm{C}$, gas flow 95 u.a., 113 auxiliary gas flow 56 u.a., corona discharge at $5 \mu \mathrm{A}$ with a voltage $4.5 \mathrm{kV}$ and capillary voltage $14 \mathrm{~V}$.

114 Mass range detection was 50-500 uma (to detect the formation of dimers). MS $^{2}$ experiments were 115 performed on protonated molecular ions in order to identify by-products. $\mathrm{MS}^{2}$ experiments were 116 performed as follows: collision energy of $35 \%$, Q activation of 0.25 and activation time of $30 \mathrm{~ms}$.

117 Analyses were performed in both APCI positive and APCI negative mode, but chloramination by118 products of ranitidine were only detected in positive mode. For the determination of ranitidine 119 decomposition kinetics, a series of ranitidine solutions at different concentrations (ranging from 0.05 $120 \mu \mathrm{M}$ to $2 \mu \mathrm{M})$ was analyzed in APCI positive mode to obtain a calibration curve $\left(\mathrm{R}^{2}=1.000\right)$. 
Ranitidine Decomposition Kinetics at Several pH. The reaction of $\mathrm{NH}_{2} \mathrm{Cl}$ with ranitidine was

124 assumed to follow second-order kinetics, first-order with respect to each reactant. The rate of ranitidine 125 decomposition in the presence of a large excess of monochloramine $\left(\left[\mathrm{NH}_{2} \mathrm{Cl}\right]_{0} /[\mathrm{RAN}]_{0}>100 \mathrm{~mol} / \mathrm{mol}\right)$ 126 can be considered as pseudo first-order with respect to ranitidine (equation 1):$$
-\frac{\mathrm{d}[\mathrm{RAN}]}{\mathrm{dt}}=\mathrm{k}_{\mathrm{obs}}[\mathrm{RAN}]
$$

$$
\text { where } \mathrm{k}_{\mathrm{obs}}=\mathrm{k}_{\mathrm{app}}\left[\mathrm{NH}_{2} \mathrm{Cl}\right]_{0}
$$

Ranitidine decomposition rates were determined at different $\mathrm{pH}$ from the reaction of $1.5 \mu \mathrm{M}$ ranitidine with $200 \mu \mathrm{M} \mathrm{NH}{ }_{2} \mathrm{Cl}$, using HPLC-MS analyses. The linear plots obtained between $\ln \left([\mathrm{RAN}] /\left[\mathrm{RAN}_{0}\right)\right.$ and reaction time confirmed the pseudo first-order rate with respect to the concentration of ranitidine

(Figure 1). At $\mathrm{pH}<5.5$, ranitidine was instantaneously decomposed and kinetics could not be studied.

133 Ranitidine chloramination rate decreased when increasing $\mathrm{pH}$, indicating an acid-catalyzed 134 decomposition (Figure 1). Ranitidine was found to exhibit a maximum NDMA formation yield around $135 \mathrm{pH} 8$ after 5 days of reaction. ${ }^{13}$ However, ranitidine decomposition did not show a maximum at $\mathrm{pH} 8$. 136 This finding indicates that the higher formation of NDMA at this $\mathrm{pH}$ and long contact times is not 137 directly related to the decomposition rate of molecular ranitidine. Moreover, previous work 138 demonstrated that the formation of NDMA was very slow (maximum NDMA formation occurring after $13924 \mathrm{~h}$ of contact $\operatorname{time}^{13}$ ) as compared to the fast decomposition rate of ranitidine observed in this study. 140 The value of $\mathrm{k}_{\mathrm{app}}$ at $\mathrm{pH} 7$ was $34.9 \mathrm{M}^{-1} \cdot \mathrm{s}^{-1}$, which is much lower than the kinetic constants obtained for 141 the chloramination of DMA $\left(7.98 .10^{8} \mathrm{M}^{-1} \cdot \mathrm{s}^{-1}\right)^{26}$ and resorcinol $\left(7.5 .10^{5} \mathrm{M}^{-1} \cdot \mathrm{s}^{-1}\right)^{23}$. Steric hindrance 142 could be responsible for the slower reaction of $\mathrm{NH}_{2} \mathrm{Cl}$ with the DMA group of ranitidine as compared to 143 DMA. Furthermore, chlorine transfer between $\mathrm{NH}_{2} \mathrm{Cl}$ and DMA is subjected to general acid 144 catalysis. $^{26,27}$ In a similar manner, chlorine transfer to the DMA group of ranitidine (i.e., electrophilic 145 substitution) could be favored at acidic $\mathrm{pH}$, which would explain the higher decomposition rate 146 observed (Figure 1). Moreover, $\mathrm{NH}_{2} \mathrm{Cl}$ decomposes at acidic $\mathrm{pH}$ by disproportionation and hydrolysis 147 and thus may create species (e.g., $\mathrm{NHCl}_{2}$ or $\left.\mathrm{HOCl}\right)$ that enhance the decomposition of ranitidine. ${ }^{28}$ 


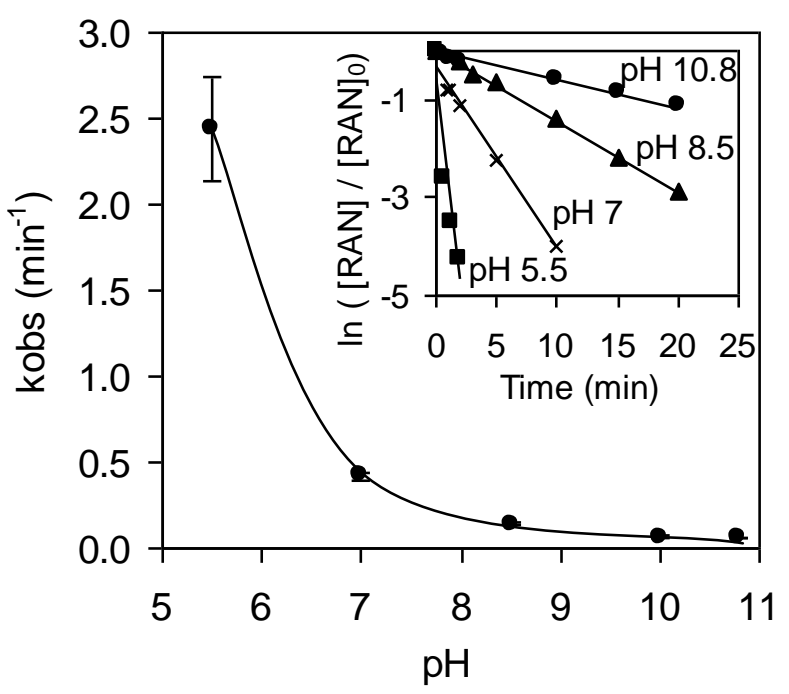

150 Figure 1. Ranitidine decomposition rates during chloramination at different $\mathrm{pH}$. $[\mathrm{RAN}]_{0}=1.5 \mu \mathrm{M}$,

$151\left[\mathrm{NH}_{2} \mathrm{Cl}\right]_{0}=200 \mu \mathrm{M}$.

Identification of Ranitidine By-products around Equimolar Conditions. Chromatographic and mass spectral data for ranitidine and its decomposition products analyzed by HPLC-MS are summarized 154 in Table 1. Structures of decomposition products are proposed based on their MS and $\mathrm{MS}^{2}$ spectral data.

155 Attempts were made to identify the reaction by-products of 5-(dimethyl-aminomethyl)furfuryl alcohol 156 (or DFUR, a molecular structure found in ranitidine and a major precursor of NDMA ${ }^{10,11}$ ) but they were 157 probably too polar to be detected in our analytical conditions.

158 Table 1. Ranitidine reaction products detected by HPLC-MS in APCI positive mode. *By-products non159 detected when reactions were stopped using sodium thiosulfate.

\begin{tabular}{llll}
\hline Compound & Fragmentation & $\begin{array}{c}\text { Nominal } \\
\text { mass }\end{array}$ & $\begin{array}{l}\text { Structure } \\
\text { (min) }\end{array}$ \\
\hline Ranitidine (RAN) & $\begin{array}{l}\mathbf{3 1 5}, 270(4 \%), 176(1.6 \%), \\
\text { NDMA }\end{array}$ & 75 & 314 \\
\hline $\begin{array}{l}\text { Dimethyl-aminomethyl furfuryl } \\
\text { alcohol (DFUR) }\end{array}$ & $\mathbf{1 5 6 , 1 1 1 ( 3 8 \% )}$ & 155 \\
\hline
\end{tabular}




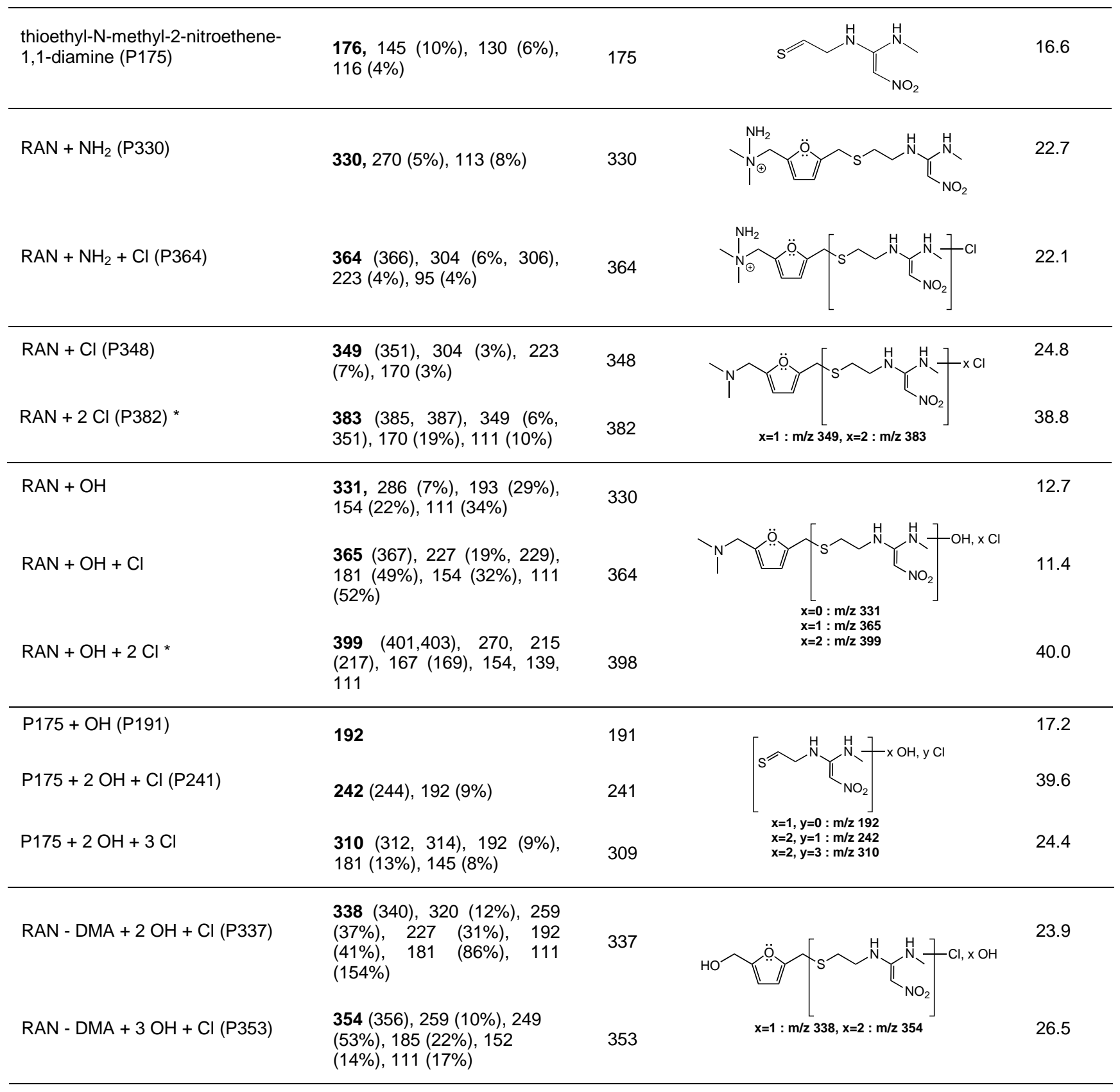

162 Ranitidine and monochloramine were introduced in the reaction buffer at $167 \mu \mathrm{M}$ and $400 \mu \mathrm{M}$, 163 respectively (similar concentration range), to identify the first compounds produced by ranitidine 164 decomposition in the presence of low concentrations of $\mathrm{NH}_{2} \mathrm{Cl}$. Major ions produced were chlorinated 165 and/or hydroxylated derivatives, i.e., m/z 331 (hydroxylated ranitidine), m/z 349 (chlorinated ranitidine), $166 \mathrm{~m} / \mathrm{z} 365$ (chlorinated and hydroxylated ranitidine), $\mathrm{m} / \mathrm{z} 383$ (ranitidine with two chlorine atoms) and $\mathrm{m} / \mathrm{z}$ 167399 (hydroxylated ranitidine with two chlorine atoms) (see SI, Figure S1). These products can result 
from chlorination and further oxidation of the N-methyl-2-nitroethene-1,1-diamine group. As proposed by Joo and Mitch for the chloramination of monomethylamine, chlorine attack on nitrogen atom and oxidation leads to the formation of organic chloramines and hydroxylamines. ${ }^{29}$ The presence of m/z 399 can be attributed to the subsequent chlorine substitution on N-methyl or ethene double bond or on the sulfur atom. Some other by-products were detected in smaller amounts. Experiments were carried out without quenching residual oxidant at the desired reaction time in order to investigate the potential influence of sodium thiosulfate on the by-products stability, because sodium thiosulfate can break N-Cl bonds formed after chlorination. ${ }^{30}$ Only products containing two chlorine atoms (i.e., molecular ions $\mathrm{m} / \mathrm{z}$ 383 and $\mathrm{m} / \mathrm{z}$ 399) were not detected when sodium thiosulfate was added. All the other by-products were detected with and without sodium thiosulfate addition. $\mathrm{MS}^{2}$ experiments were conducted on ranitidine and the above-mentioned by-products to determine the position of chlorine substitution and hydroxylation. Figure S2a in SI gives the $\mathrm{MS}^{2}$ spectrum obtained for ranitidine. A loss of dimethylamine (DMA) group (45 Da) gave the fragment ion $\mathrm{m} / \mathrm{z} 270$, and the following loss of $\mathrm{NO}_{2}$ radical ion (46 Da) 181 generated the radical fragment ion $\mathrm{m} / \mathrm{z} 224$. Different ruptures of $\mathrm{C}-\mathrm{S}$ bonds led to the formation of fragments $\mathrm{m} / \mathrm{z} 176,144$ and 124 . These results are in accordance with $\mathrm{MS}^{2}$ fragments observed in a previous study by Radjenović et al., ${ }^{31}$ using a quadrupole-time of flight (Q-Tof) detection. In the same study, the compound with molecular ion m/z 331 has been identified as a photocatalytic by-product of ranitidine. ${ }^{31}$ The difference of $16 \mathrm{Da}$ was attributed to the hydroxylation of ranitidine. $\mathrm{MS}^{2}$ experiments on this molecular ion revealed similar fragments than those observed by Radjenović et al. ${ }^{31}$ (See SI, Figure S3b). The typical loss of DMA group led to the fragment m/z 286 and further loss of water led to the fragment $\mathrm{m} / \mathrm{z} 268$, which confirms the hydroxylation of ranitidine. Different ruptures of C-S bonds in the molecular ion m/z 331 generated pairs of fragments m/z 156 and 176, and fragments m/z 188 and 143. Fragment ion $\mathrm{m} / \mathrm{z} 156$ can be attributed to the previously mentioned DFUR, i.e. the hydroxylated 191 dimethylaminomethylfuran group. Dehydroxylation of DFUR led to the fragment m/z 138 (Figure S3). 192 By comparing the $\mathrm{MS}^{2}$ fragments of chlorinated ranitidine (m/z 349) with that of ranitidine (m/z 315), 193 several similarities could be observed (see SI, Figure S2). Losses of DMA and $\mathrm{NO}_{2}$ groups from 
chlorinated ranitidine generated chlorinated fragments $\mathrm{m} / \mathrm{z} 304$ and 258 . This indicates that chlorine

195

196

197

198

199

transfer did not occur on the dimethylamino group as it was previously suggested during chloramination of tertiary amines. ${ }^{32}$ This implies that chlorine transfer leading to the release of DMA is not a pathway of NDMA formation by chloramination of ranitidine. Moreover, the major fragment ion of chlorinated ranitidine was $\mathrm{m} / \mathrm{z} 210$. This fragment is the chlorinated analogue of the fragment ion $\mathrm{m} / \mathrm{z} 176$ of ranitidine, which indicates that chlorine substitution does not occur on the furan group but probably on nitrogen or sulfur atoms. This is confirmed by the fact that a chlorinated analogue of $\mathrm{m} / \mathrm{z} 124$ (i.e. the dimethylaminomethylfuran fragment) was not detected.

Some minor by-products exhibited a gain of $15 \mathrm{Da}$ as compared to molecular ranitidine and chlorinated ranitidine. Chromatograms exhibited small peaks with a molecular ion $\mathrm{m} / \mathrm{z} 330$ (intermediate product P330) and a molecular ion m/z 364 (P364) at retention times of 22.7 min and 22.1 min, respectively. P364 was identified as the chlorinated analogue of P330. The observation of such products is consistent with the occurrence of a nucleophilic substitution between $\mathrm{NH}_{2}$ group of monochloramine and the DMA group of ranitidine, leading to a gain of $15 \mathrm{Da}$ as compared to ranitidine (i.e. P330) (Scheme 1). Moreover, the odd nominal mass of this product indicates an odd number of nitrogen atoms, confirming the gain of a nitrogen atom as compared to ranitidine. The relatively low abundance of this peak suggests that it is rapidly decomposed to other degradation by-products. $\mathrm{MS}^{2}$ experiment conducted on P330 generated the same fragments as ranitidine (i.e., m/z 270, 258, 224, 176 and 124, Figure S3). This indicates that the fragmentation of $\mathrm{P} 330$ leads to the loss of the $\mathrm{NH}_{2}$ group, probably because of a weak bond. $\mathrm{MS}^{2}$ fragmentation of the chlorinated analogue of P330 did not provide any additional information.

Influence of $\mathrm{NH}_{2} \mathrm{Cl}$ Concentration. The reaction between ranitidine $(167 \mu \mathrm{M})$ and various concentrations of $\mathrm{NH}_{2} \mathrm{Cl}$ (ranging from 0 to $1 \mathrm{mM}$ ) after $2 \mathrm{~h}$ of reaction time at $\mathrm{pH} 8$ (with $10 \mathrm{mM}$ phosphate buffer) was monitored using HPLC-MS (Figure 2). Decomposition rate of ranitidine increased with increasing $\mathrm{NH}_{2} \mathrm{Cl}$ concentration until full degradation for concentrations greater than 0.5 
$220 \mathrm{mM}$. The formation of chlorinated ranitidine (i.e., $\mathrm{m} / \mathrm{z}$ 349) decreased with increasing $\mathrm{NH}_{2} \mathrm{Cl}$ 221 concentration. Maximum chlorinated ranitidine formation occurred when ranitidine and $\mathrm{NH}_{2} \mathrm{Cl}$ were 222 introduced in equimolar concentrations.

223 Most of the major by-products were preferentially formed for a $\mathrm{NH}_{2} \mathrm{Cl} /$ ranitidine ratio of 224 approximately $2 \mathrm{~mol} / \mathrm{mol}$ (e.g., m/z 176, 192, 330, 331, 364, 365) (Figure 2). By-products with 225 molecular ions m/z $176(\mathrm{P} 175)$ and $\mathrm{m} / \mathrm{z} 192$ (P191) were detected at retention times of $16.6 \mathrm{~min}$ and 22617.2 min respectively. P191 was identified as the hydroxylated analogue of P175 (i.e. the thioethyl-N227 methyl-2-nitroethene-1,1-diamine moiety). NDMA formation occurred only for a $\mathrm{NH}_{2} \mathrm{Cl}$ concentration 228 of $1 \mathrm{mM}$, i.e. in a large excess of $\mathrm{NH}_{2} \mathrm{Cl}$, and after disappearance of the other by-products. Products 229 P330 and P364 (postulated as resulting from nucleophilic substitution on the DMA group of ranitidine) 230 were totally degraded at $\mathrm{NH}_{2} \mathrm{Cl}$ concentrations where NDMA formed (i.e., $1 \mathrm{mM}$ ), observation 231 consistent with their potential implication as intermediate compounds involved in the formation of 232 NDMA. 


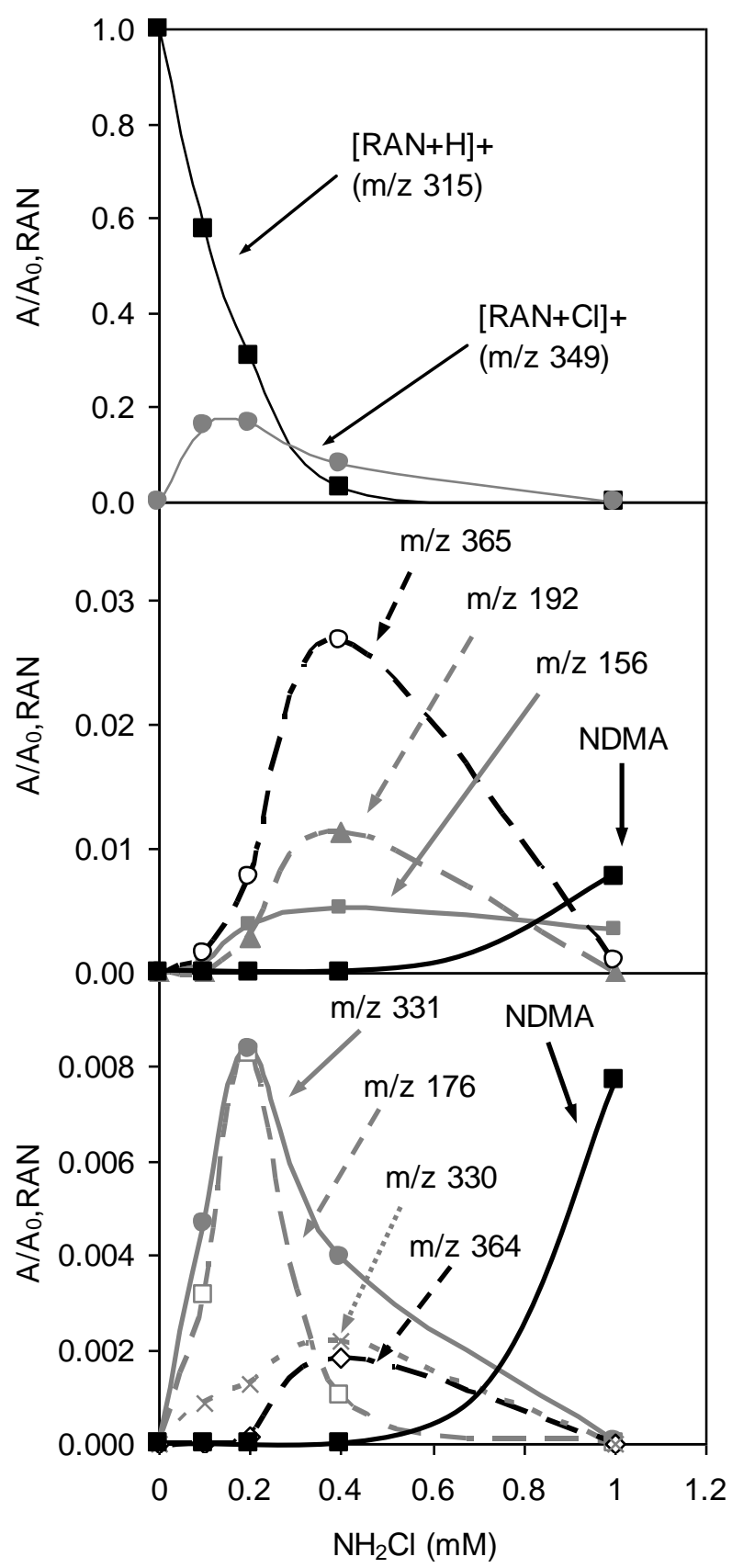

234 Figure 2. Influence of $\mathrm{NH}_{2} \mathrm{Cl}$ concentration on the decomposition of ranitidine and the formation of 235 ranitidine by-products. $[\mathrm{RAN}]_{0}=167 \mu \mathrm{M}, \mathrm{t}=2 \mathrm{~h}, \mathrm{pH}=8$. Relative scale based on initial ranitidine 236 concentration.

237 Ranitidine By-products Formed in Excess of Monochloramine. In order to determine the by238 products formed in the presence of an excess of monochloramine, i.e. in the conditions where NDMA 239 formation is favored, the decomposition of ranitidine $(12 \mu \mathrm{M})$ was investigated in the presence of 2.5 $240 \mathrm{mM} \mathrm{NH}_{2} \mathrm{Cl}$ over $48 \mathrm{~h}$ at $\mathrm{pH} 8$ (with $10 \mathrm{mM}$ phosphate buffer). These conditions have been 
241 demonstrated to maximize the formation of NDMA. ${ }^{13}$ Decomposition of ranitidine was complete in less

242 than 2 min, while the formation of NDMA was much slower (Figure 3a). Chlorine transfer (i.e., the 243 formation of chlorinated ranitidine) was very fast and chlorinated ranitidine was entirely decomposed in 244 less than $2 \mathrm{~min}$ as well as ranitidine. NDMA formation reached a plateau after $75 \mathrm{~min}$. This is in 245 agreement with our previous observations of NDMA formation in similar conditions and monitored by 246 GC/MS. ${ }^{13}$ Products that were previously detected when $\mathrm{NH}_{2} \mathrm{Cl}$ was introduced at equimolar 247 concentrations or with a slight excess as compared to ranitidine (e.g., fragments m/z 156, 330, 331, 364, 248 365, Figure 2) were not detected, probably because they were rapidly decomposed in the presence of a 249 large excess of $\mathrm{NH}_{2} \mathrm{Cl}$ (Figure $3 b$ ).
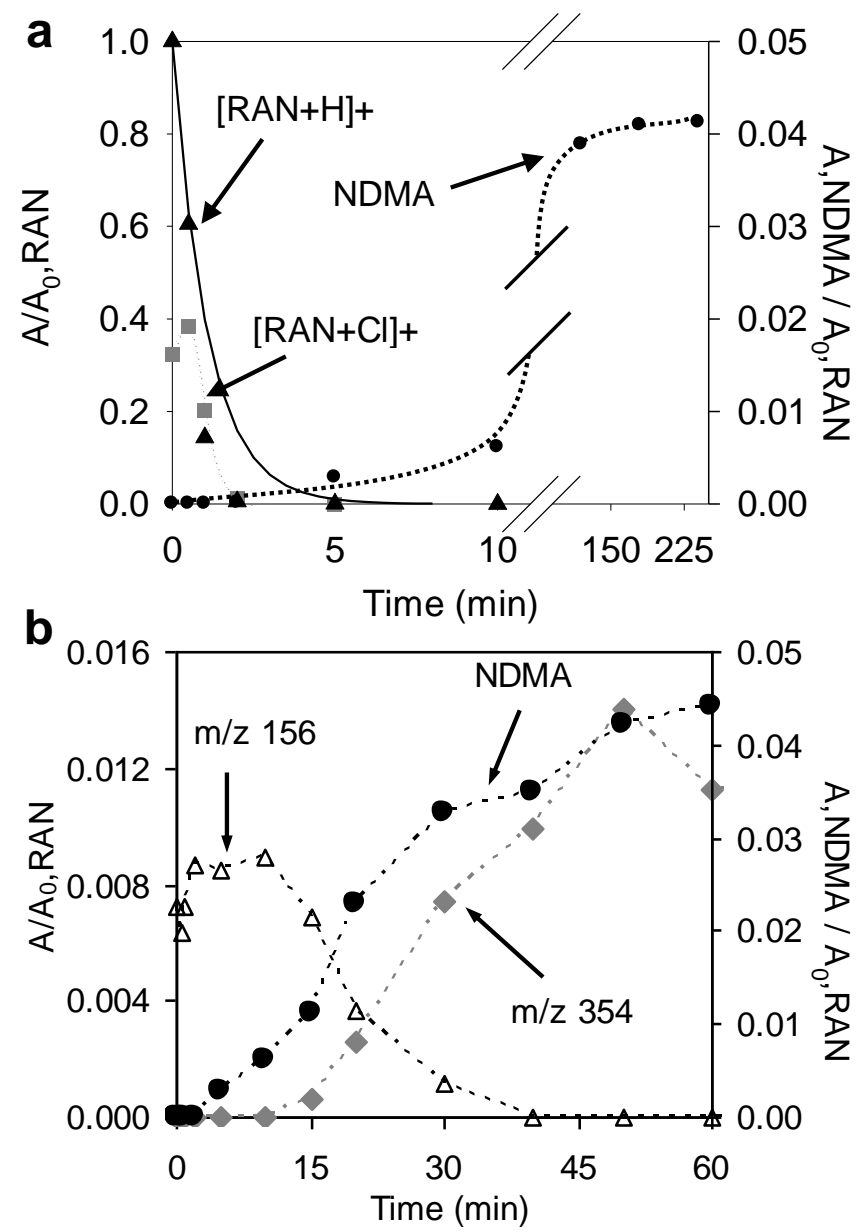

251 Figure 3. Decomposition of ranitidine (a) and formation of NDMA and other by-products (a and b) by 252 chloramination monitored by HPLC-MS in APCI positive mode. $[\mathrm{RAN}]_{0}=12 \mu \mathrm{M} ;\left[\mathrm{NH}{ }_{2} \mathrm{Cl}\right]_{0}=2.5 \mathrm{mM}$; 
$253 \mathrm{pH}=8$ with $10 \mathrm{mM}$ phosphate buffer. Relative area is based on initial ranitidine concentration. Solid

254 line (a) represents model values of ranitidine decomposition based on the rate constant obtained at $\mathrm{pH} 8$.

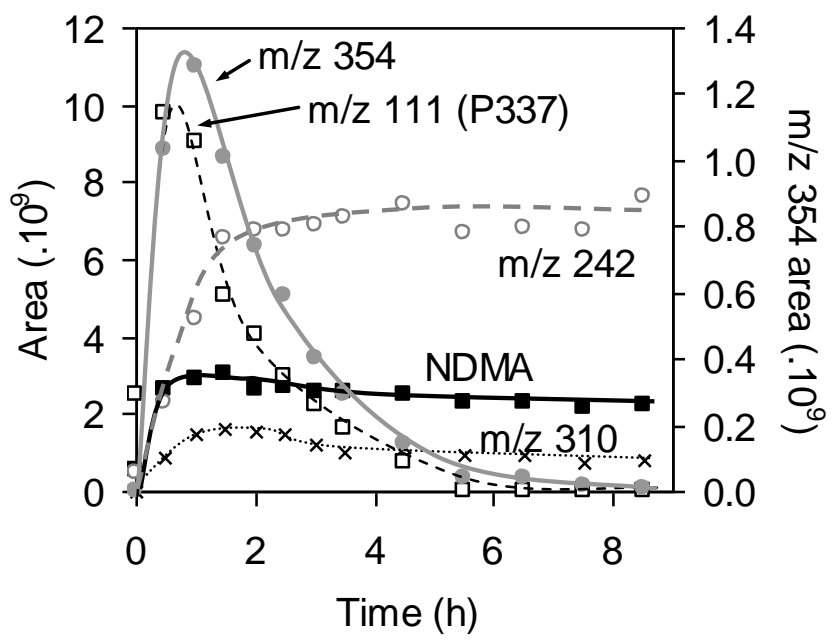

257 Figure 4. Formation of NDMA and other by-products by chloramination of ranitidine monitored by 258 HPLC-MS in APCI positive mode. $[\mathrm{RAN}]_{0}=120 \mu \mathrm{M} ;\left[\mathrm{NH}_{2} \mathrm{Cl}\right]_{0}=10 \mathrm{mM} ; \mathrm{pH}=8$. Lines represent best 259 fits of data.

260 Figure 4 depicts the formation of ranitidine by-products for higher initial concentrations (i.e., $120 \mu \mathrm{M}$ 261 of ranitidine and $10 \mathrm{mM}$ of $\mathrm{NH}_{2} \mathrm{Cl}$ ) and longer contact times. Different products were slowly formed 262 along with NDMA (m/z 111, 242, 310, and 354). NDMA (m/z = 75) and products with molecular ions $263 \mathrm{~m} / \mathrm{z} 242$ and m/z 310 reached a plateau after $30 \mathrm{~min}$ of contact time. The product with a molecular ion $264 \mathrm{~m} / \mathrm{z} 242(\mathrm{P} 241)$ was generated by hydroxylation and chlorination of P175, probably on nitrogen atoms 265 of the N-methyl-2-nitroethene-1,1-diamine moiety as previously mentioned for molecular ranitidine. 266 Subsequent chlorination of P241 led to the product with a molecular ion $\mathrm{m} / \mathrm{z} 310$ (the presence of 3 267 chlorine atoms was confirmed by its isotopic distribution).

268 The ion $\mathrm{m} / \mathrm{z} 111$ was identified as the major fragment of the molecular ion $\mathrm{m} / \mathrm{z} 338$ (P337) (see Table 269 1). The odd nominal mass of this product indicates an odd number of nitrogen atoms, reflecting the loss 270 of the DMA group. MS spectra of this product revealed the presence of a chlorine atom and a gain of 32 271 Da. This molecule can be attributed to the dihydroxylation and chlorination of ranitidine after the loss of 
the DMA group (corresponding to fragment $\mathrm{m} / \mathrm{z} 270$ ). The product with molecular ion $\mathrm{m} / \mathrm{z} 354$ (P353)

was identified as a hydroxylated analogue of P337, thus explaining the short delay between the

formations of these products (Figure 4). P337 and P353 reached a maximum after around $1 \mathrm{~h}$ of reaction

and then slowly decreased. Their formation was strongly correlated to NDMA formation during the first

45 min of reaction. Hence, these compounds may be products resulting from carbocation intermediates formed during the last step of NDMA formation, as discussed below.

Influence of Free Chlorine. The influence of free chlorine $(180 \mu \mathrm{M} \mathrm{HOCl})$ on ranitidine $(180 \mu \mathrm{M})$ was investigated to compare chlorination and chloramination by-products produced at $\mathrm{pH} 8$ and after $2 \mathrm{~h}$ of contact time. Similar chlorinated and hydroxylated by-products (i.e., molecular ions m/z 156, 176, 192, $331,349,365)$ were formed after chlorination and chloramination and exhibited similar responses.

However, P330 and P364 (chlorinated analogue of P330) were not detected in the presence of HOCl.

This confirms the hypothesis of a nucleophilic substitution between $\mathrm{NH}_{2} \mathrm{Cl}$ and the DMA group of ranitidine, leading to the P330 intermediate. Subsequent electrophilic substitution of P330 gives the chlorinated analogue P364.

\section{Proposed NDMA Formation Pathway}

During chloramination of amines, either chlorine transfer or nucleophilic substitution can occur. Chlorine transfer from $\mathrm{NH}_{2} \mathrm{Cl}$ to the nitrogen atom of the DMA group of ranitidine is unlikely to occur as a predominant pathway because it would only lead to the formation of DMA or dimethylchloramine (DMCA) that are minor precursors of NDMA (i.e., $<3 \%$ molar yields). ${ }^{2,6,7}$ Several tertiary amines have been demonstrated to produce important yields of NDMA, especially ranitidine ( $>60 \%$ molar yield), ${ }^{11-13}$ and more recently dimethylbenzylamine (64\% molar yield). ${ }^{17}$ Hence, a chlorine transfer (i.e., electrophilic substitution) cannot explain the high yields of NDMA obtained for those tertiary amines.

The formation of NDMA by chloramination of DMA was previously proposed to occur via the formation of an UDMH, UDMH-Cl or UDMH-Br intermediate, followed by an oxidation in the 
presence of dissolved oxygen. ${ }^{6,7,9,10}$ This last step of the mechanism remains quite unclear because the kinetics of UDMH oxidation have not been clearly investigated in the presence of both dissolved oxygen and $\mathrm{NH}_{2} \mathrm{Cl}$. UDMH (m/z 61) or equivalent intermediates UDMH-Cl (m/z 95) and UDMH-Br $(\mathrm{m} / \mathrm{z} 139)$ 301 were not detected in our analysis conditions. They were probably not separated correctly by liquid oxidized to NDMA in the presence of dissolved oxygen and monochloramine or free chlorine, which explains why they have never been observed when NDMA was formed during chlorination or chloramination of water solutions containing amines. ${ }^{7,8}$ Experiments were conducted to investigate the formation of NDMA by oxidation of UDMH $(500 \mathrm{nM})$ by $\mathrm{NH}_{2} \mathrm{Cl}(2.5 \mathrm{mM})$ in the presence of dissolved oxygen. Molar yields after $24 \mathrm{~h}$ of contact time were very low (i.e., $<0.01 \%$ ) as compared to NDMA formation from ranitidine (i.e., $>60 \%$ ). Our results are in accordance with several studies that investigated UDMH oxidation by dissolved oxygen or $\mathrm{NH}_{2} \mathrm{Cl}^{33-35}$ Hence, these results suggest that UDMH is not likely to be a major intermediate involved in the formation of NDMA during chloramination, especially from tertiary amines such as ranitidine.

Based on these observations, we propose that DMA groups must be attached at the benzylic position of aromatic or heterocyclic rings in order to produce high yields of NDMA. Indeed, as shown in Scheme 1, the release of NDMA from ranitidine leads to the formation of a stable carbocation at benzylic position of the furan ring that is favored thermodynamically. These carbocation intermediates are prone to react with nucleophiles such as water and thus may lead to the observed products P337 and P353 after hydroxylation on the methylene group. This mechanism is in accordance with the simultaneous production of P337, P353 and NDMA observed during chloramination of ranitidine (Figure 4).

In a previous study, we demonstrated that almost no NDMA was formed in the absence of dissolved oxygen during chloramination of ranitidine. ${ }^{13}$ Because the formation of UDMH and its oxidation by dissolved oxygen is not likely to occur, dissolved oxygen incorporation has to occur directly on the intermediate formed after the reaction between $\mathrm{NH}_{2} \mathrm{Cl}$ and the DMA group of ranitidine (i.e. products P330 or P364). Hence, we propose that the positive charge on the nitrogen atom of the DMA moiety 
reduces the $\mathrm{pKa}$ of hydrogen on the $\mathrm{NH}_{2}$ group, therefore favoring the formation of a highly reactive

$\mathrm{NH}^{-}$intermediate which reacts with dissolved oxygen to yield a NDMA precursor group.

We hypothesize that nucleophilic substitution rather than chlorine transfer is the main reaction occurring on the DMA moiety of ranitidine. In this case the steric hindrance brought by the two methyl groups probably disfavors the transfer of the bulky chlorine atom of $\mathrm{NH}_{2} \mathrm{Cl}$ to the amine. However, chlorine transfer is likely to take place on less hindered moieties of ranitidine, especially on nitrogen atoms of the thioethyl-N-methyl-2-nitroethene-1,1-diamine moiety, producing the chlorinated analogues

331 of ranitidine (i.e., $\mathrm{m} / \mathrm{z} 349$ and $\mathrm{m} / \mathrm{z} 383$ ) and then hydroxylated analogues after further oxidation.

332 Chlorine transfer can also take place on the sulfur atom and cause sulfoxide compounds formation, ${ }^{36}$ or 333 the cleavage of the $\mathrm{C}-\mathrm{S}$ bond leading to the release of the observed product P175 and 334 5-(dimethylaminomethyl)furfuryl alcohol (DFUR, m/z 156) (see SI, Scheme S1). Our results are 335 consistent with three initial reactions: i) fast chlorine transfer leading to chlorinated analogues of 336 ranitidine, ii) the cleavage of the C-S bond leading to DFUR and iii) nucleophilic substitution leading to 337 P330. The proposed pathways are also probably interconnected because chlorinated ranitidine (P348) 338 can also react with $\mathrm{NH}_{2} \mathrm{Cl}$ through nucleophilic substitution and lead to $\mathrm{P} 364$, and both hydroxylated and chlorinated ranitidine analogues can liberate DFUR through the cleavage of C-S bond. DFUR is 340 known to be a decomposition product of ranitidine, ${ }^{37}$ and to produce important amounts of NDMA as 341 well as ranitidine (i.e., $>50 \%$ molar yields). ${ }^{10,11}$ Hence, DFUR produced via chlorine addition on 342 ranitidine and $\mathrm{C}-\mathrm{S}$ bond cleavage could react with $\mathrm{NH}_{2} \mathrm{Cl}$ to contribute to the overall formation of 343 NDMA. The stable carbocation (i.e. methylfurfuryl alcohol) that would form along with NDMA via this 344 pathway and its hydroxylated analogue were not detected, probably because they were not properly 345 separated in our chromatographic conditions.

348 Scheme 1. NDMA formation mechanism proposed for the chloramination of ranitidine (N.D. = Not 349 Detected). 


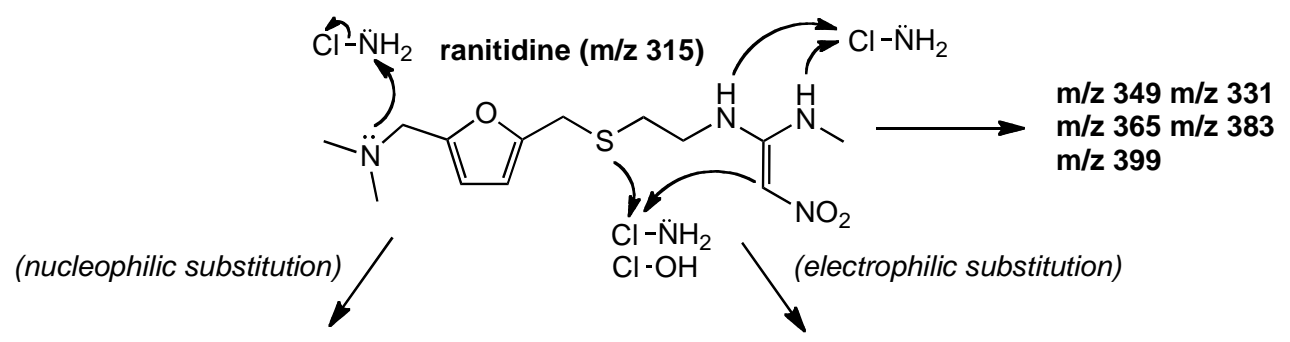<smiles>[X]C(Cl)(Cl)Cc1ccc(C[N+](C)(C)N)o1</smiles>

$x=0: m / z 330, x=1: m / z 364$<smiles>CCO[C@@H]([PH2+])I</smiles><smiles>CC[N-][N+](C)(C)Cc1ccc(CSCCNC(=C[N+](=O)[O-])NC)o1</smiles><smiles>C[PH+]CO[Co]</smiles>

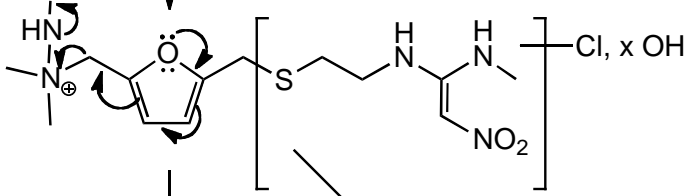

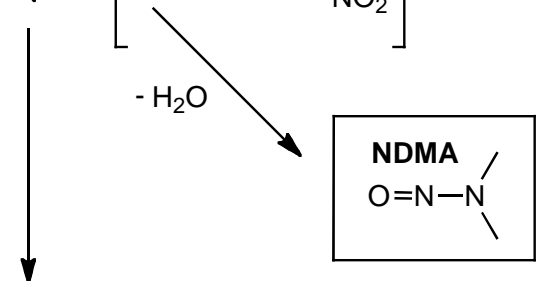

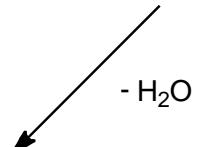

\section{$\mathrm{H}_{2} \mathrm{O}$}

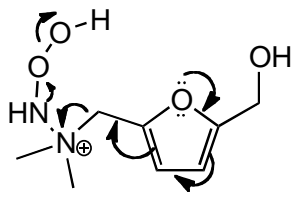

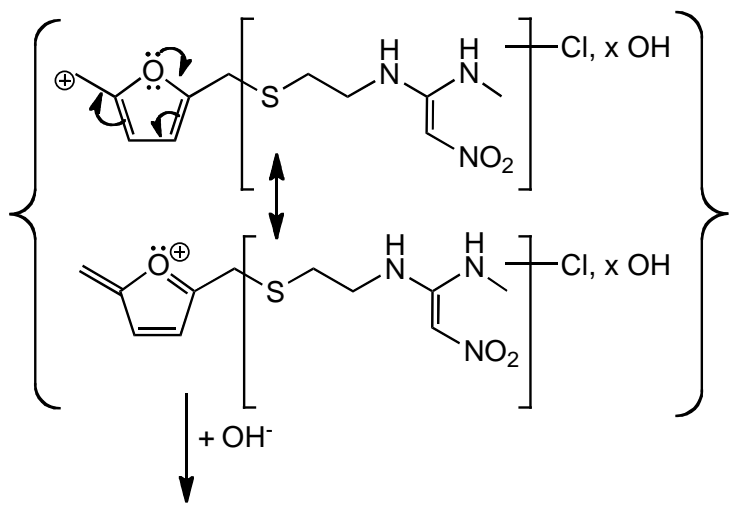<smiles>CN(C)Cc1ccc(CO)o1</smiles>

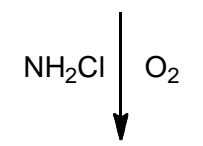
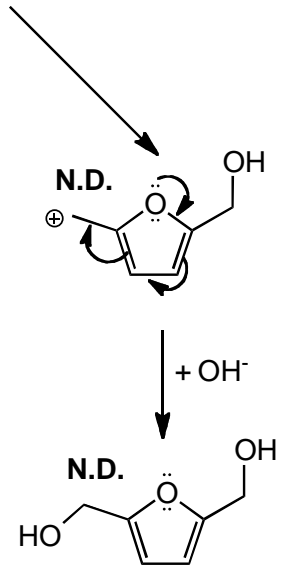
The kinetics study revealed that ranitidine decomposition was favored at acidic $\mathrm{pH}$, while NDMA

354 formation reaches a maximum around $\mathrm{pH} 8 .{ }^{13}$ Hence, NDMA formation cannot be directly related to the decomposition of molecular ranitidine. The influence of $\mathrm{pH}$ on NDMA formation depends on complex reactions involving monochloramine stability, the potential formation of chloramines decomposition products (e.g., peroxynitrite ions or hydrazine intermediates), or acid dissociation constants of ranitidine and its by-products. Even if the disproportionation of $\mathrm{NH}_{2} \mathrm{Cl}$ to $\mathrm{NHCl}_{2}$ has been proposed to favor the formation of NDMA from the reaction with $\mathrm{DMA}^{8}$ the decomposition of $\mathrm{NH}_{2} \mathrm{Cl}$ at acidic $\mathrm{pH}$ is expected to limit the production of NDMA in the case of ranitidine oxidation. ${ }^{13}$ Moreover, no analogue 361 to P330 with a chlorine atom on the amine group (i.e., $\mathrm{RAN}+\mathrm{NHCl}$ ) was detected, as it could be expected to form from the reaction of ranitidine with dichloramine. In our experimental conditions (i.e.,

$363 \mathrm{pH} 8$ ), the production of $\mathrm{NHCl}_{2}$ was limited. Hence, $\mathrm{NHCl}_{2}$ does not seem to play a major role in the 364 formation of NDMA during chloramination of ranitidine, as we already proposed in a previous study. ${ }^{13}$ 365 Chlorine transfer between $\mathrm{NH}_{2} \mathrm{Cl}$ and DMA is also subjected to general acid catalysis. ${ }^{25,27}$ In a similar 366 manner, chlorine transfer to the DMA group of ranitidine (i.e., electrophilic substitution) could be 367 favored at acidic $\mathrm{pH}$, which would explain the higher decomposition rate observed (Figure 1), and thus 368 electrophilic substitution (i.e., chlorine attack) at $\mathrm{pH}<7$.

371 Many by-products were identified during the chloramination of ranitidine. Different compounds are observed. In real water disinfection conditions, ranitidine (or another major precursor of NDMA) is expected to be at very low concentrations (i.e. at ng/L levels) as compared to $\mathrm{NH}_{2} \mathrm{Cl}$ concentrations. 
378 be limited by lowering the $\mathrm{pH}$ or by reducing the initial concentration of ranitidine (or other NDMA 379 precursors).

380 Acknowledgments. The authors thank the French Ministry of Higher Education and Research 381 (Ministère de l'Enseignement Supérieur et de la Recherche) for its financial support. The authors would 382 also like to thank Emilie Caupos for her assistance during the analyses.

383 Supporting Information. Additional details of the materials and methods, additional figures 384 (chromatogram and MS spectra of ranitidine and several by-products) and scheme of P155 (DFUR) and 385 P175 formation.

\section{Literature Cited}

(1) Gerecke, A. C.; Sedlak, D. L. Precursors of N-nitrosodimethylamine in natural waters. Environ. Sci. Technol. 2003, 37 (7), 1331-1336.

(2) Mitch, W. A.; Sedlak, D. L. Characterization and Fate of N-Nitrosodimethylamine Precursors in Municipal Wastewater Treatment Plants. Environ. Sci. Technol. 2004, 38 (5), 1445-1454.

(3) U.S. Environmental Protection Agency (1987) Integrated Risk Information System (IRIS), Nnitrosodimethylamine. Office of Research and Development (ORD), National Center for Environmental Assessment. Available online from www.epa.gov/iris/subst/0045.htm, accessed October 20, 2011.

(4) U.S. Environmental Protection Agency (2009) Contaminant Candidate List 3 - CCL, 2009. Available online from http://water.epa.gov/scitech/drinkingwater/dws/ccl/ccl3.cfm, accessed May $15,2012$.

(5) Choi, J.; Valentine, R. L. N-Nitrosodimethylamine Formation by Free-Chlorine-Enhanced Nitrosation of Dimethylamine. Environ. Sci. Technol. 2003, 37 (21), 4871-4876. 
(6) Choi, J.; Valentine, R. L. Formation of N-nitrosodimethylamine (NDMA) from reaction of monochloramine: A new disinfection by-product. Water Res. 2002, 36 (4), 817-824.

403 (7) Mitch, W. A.; Sedlak, D. L. Formation of N-nitrosodimethylamine (NDMA) from dimethylamine 404

(9) Chen, Z.; Yang, L.; Zhai, X.; Zhao, S.; Li, A.; Shen, J. N-nitrosamine formation during chlorination/chloramination of bromide-containing water. Water Sci. Technol.: Water Supply 2010, $10(3), 462-471$.

(10) Le Roux, J.; Gallard, H.; Croué, J. P. Formation of NDMA and Halogenated DBPs by Chloramination of Tertiary Amines: The Influence of Bromide Ion. Environ. Sci. Technol. 2012, $46(3), 1581-1589$.

(11) Schmidt, C. K.; Sacher, F.; Brauch, H. (2006) Strategies for minimizing formation of NDMA and other nitrosamines during disinfection of drinking water. Proceedings of the American Water Works Association Water Quality Technology Conference, Denver, CO.

(12) Shen, R.; Andrews, S. A. Demonstration of 20 pharmaceuticals and personal care products (PPCPs) as nitrosamine precursors during chloramine disinfection. Water Res. 2011, 45 (2), 944952.

(13) Le Roux, J.; Gallard, H.; Croué, J. P. Chloramination of nitrogenous contaminants (pharmaceuticals and pesticides): NDMA and halogenated DBPs formation. Water Res. 2011, 45 (10), 3164-3174.

(14) Fent, K.; Weston, A. A.; Caminada, D. Ecotoxicology of human pharmaceuticals. Aquatic Toxicology 2006, 76 (2), 122-159. 
(15) Batt, A. L.; Kostich, M. S.; Lazorchak, J. M. Analysis of ecologically relevant pharmaceuticals in wastewater and surface water using selective solid-phase extraction and UPLC-MS/MS. Anal. Chem. 2008, 80 (13), 5021-5030.

(16) Terzić, S.; Senta, I.; Ahel, M.; Gros, M.; Petrović, M.; Barcelo, D.; Müller, J.; Knepper, T.; Martí, I.; Ventura, F. et al. Occurrence and fate of emerging wastewater contaminants in Western Balkan Region. Science of The Total Environment 2008, 399 (1-3), 66-77.

(17) Kemper, J. M.; Walse, S. S.; Mitch, W. A. Quaternary amines as nitrosamine precursors: A role for consumer products? Environ. Sci. Technol. 2010, 44 (4), 1224-1231.

(18) Zuccato, E.; Castiglioni, S.; Fanelli, R. Identification of the pharmaceuticals for human use contaminating the Italian aquatic environment. J. Hazard. Mater. 2005, 122 (3), 205-209.

(19) Zuccato, E.; Calamari, D.; Natangelo, M.; Fanelli, R. Presence of therapeutic drugs in the environment. The Lancet 2000, 355 (9217), 1789-1790.

(20) Kolpin, D. W.; Furlong, E. T.; Meyer, M. T.; Thurman, E. M.; Zaugg, S. D.; Barber, L. B.; Buxton, H. T. Pharmaceuticals, Hormones, and Other Organic Wastewater Contaminants in U.S. Streams, 1999-2000: A National Reconnaissance. Environ. Sci. Technol. 2002, 36 (6), 1202-1211.

(21) Latch, D. E.; Stender, B. L.; Packer, J. L.; Arnold, W. A.; McNeill, K. Photochemical fate of pharmaceuticals in the environment: Cimetidine and ranitidine. Environ. Sci. Technol. 2003, 37 (15), 3342-3350.

(22) Isidori, M.; Parrella, A.; Pistillo, P.; Temussi, F. Effects of ranitidine and its photoderivatives in the aquatic environment. Environment International 2009, 35 (5), 821-825.

(23) Cimetiere, N.; Dossier-Berne, F.; De Laat, J. Monochloramination of resorcinol: Mechanism and kinetic modeling. Environ. Sci. Technol. 2009, 43 (24), 9380-9385. 
(24) Shen, R.; Andrews, S. A. NDMA formation kinetics from three pharmaceuticals in four water matrices. Water Res. 2011, 45 (17), 5687-5694.

(25) Schreiber, I. M.; Mitch, W. A. Influence of the order of reagent addition on NDMA formation during chloramination. Environ. Sci. Technol. 2005, 39 (10), 3811-3818.

(26) Isaac, R. A.; Morris, J. C. Transfer of active chlorine from chloramine to nitrogenous organic compounds. 2. Mechanism. Environ. Sci. Technol. 1985, 19 (9), 810-814.

(27) Ferriol, M.; Gazet, J.; Saugier-Cohen Adad, M. Kinetics and mechanisms of chlorine transfer from chloramine to amines in aqueous medium. International Journal of Chemical Kinetics 1991, 23 (4), 315-329.

(28) Jafvert, C. T.; Valentine, R. L. Reaction scheme for the chlorination of ammoniacal water. Environ. Sci. Technol. 1992, 26 (3), 577-786.

(29) Joo, S. H.; Mitch, W. A. Nitrile, Aldehyde, and Halonitroalkane Formation during Chlorination/Chloramination of Primary Amines. Environ. Sci. Technol. 2007, 41 (4), 1288-1296.

(30) Pinkston, K.E.; Sedlak, D.L. Transformation of aromatic ether- and amine-containing pharmaceuticals during chlorine disinfection. Environ. Sci. Technol. 2004, 38, 4019-4025.

(31) Radjenović, J.; Sirtori, C.; Petrović, M.; Barceló, D.; Malato, S. Characterization of intermediate products of solar photocatalytic degradation of ranitidine at pilot-scale. Chemosphere 2010, 79 (4), 368-376.

(32) Mitch, W. A.; Schreiber, I. M. Degradation of tertiary alkylamines during chlorination/chloramination: Implications for formation of aldehydes, nitriles, halonitroalkanes, and nitrosamines. Environ. Sci. Technol. 2008, 42 (13), 4811-4817.

(33) Mathur, M. A.; Sisler, H. H. Oxidation of 1,1-dimethylhydrazine by oxygen. Inorganic Chemistry 1981, 20 (2), 426-429. 
(34) Lunn, G. \& Sansone, E. B. Oxidation of 1,1-dimethylhydrazine (UDMH) in aqueous solution with air and hydrogen peroxide. Chemosphere 1994, 29 (7), 1577-1590.

(35) Lunn, G.; Sansone, E. B.; Andrews, A. W. Aerial oxidation of hydrazines to nitrosamines. Environ. Mol. Mutagen. 1991, 17 (1), 59-62.

(36) Deborde, M.; von Gunten, U. Reactions of chlorine with inorganic and organic compounds during water treatment-Kinetics and mechanisms: A critical review. Water Res. 42 (1-2), 13-51

(37) Guerrieri, P. P.; Smith, D. T.; Taylor, L. S. Phase behavior of ranitidine $\mathrm{HCl}$ in the presence of degradants and atmospheric moisture-impact on chemical stability. Langmuir 2008, 24 (8), 38503856.

\section{Ranitidine + Monochloramine}

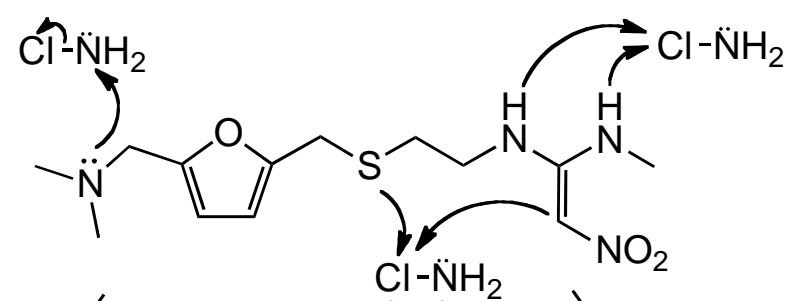

nucleophilic substitution

NDMA

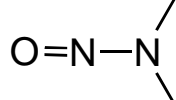

$\mathrm{Cl} \cdot \mathrm{OH}^{2}$

electrophilic substitution

Chlorinated by-products 